\title{
Nanoparticles engineered from endophytic fungi (Botryosphaeria rhodina) against ESBL-producing pathogenic multidrug-resistant E. coli
}

Tahira Akther ${ }^{\dagger}$, S. Ranjani ${ }^{\dagger}$ and S. Hemalatha* ${ }^{*}$

\begin{abstract}
Background: ESBLs hydrolyze the beta-lactam ring of antibiotics and are not affected by $1 \mathrm{st}, 2 \mathrm{nd}$, 3rd, and 4th generation antibiotics. There are over $400 \mathrm{ESBL}$ enzymes that have already been investigated globally are present in Enterobacteriaceae species such as Escherichia coli, Klebsiella pneumoniae and Klebsiella oxytoca strains. Prevalence of ESBLs is slowly increased, from 10 to $40 \%$ in E. coli and K. pneumonia strains. Microorganisms producing ESBLs are challenging to physicians, clinical microbiologists, and antibiotic researchers.

Results: In this study, ESBL-producing strains of E. coli were subjected to antibiotic sensitivity screening. The efficacy of myco BR-AgNPs on growth in E. coli ATCC (25922) and clinical isolates of E. coli was determined by well diffusion method. Myco BR-AgNPs reduced the growth as well as inhibited the biofilm formation in ESBL-producing strains of E. coli. MIC and MBC were determined by using serial microdilution and surface drop method. The MICs were 0.078$0.625 \mu \mathrm{g} / \mathrm{ml}$ and MBCs were $0.312-1.25 \mu \mathrm{g} / \mathrm{ml}$. The biofilm formation was effectively inhibited by myco BR-AgNPs when compared with control. The expression of CTX-M-15 gene was studied in clinical isolates of E. coli treated with antibiotic (positive control), mycosilver nanoparticles (test) and compared with the other positive control (untreated strains). Interestingly, the expression of CTX-M-15 was downregulated in the samples treated with myco BR-AgNPs.

Conclusion: The use of myco BR-AgNPs and their growth inhibitory effect on ESBL-positive strains were the main focus of this research. ATCC and ESBL strains used in this study were effectively inhibited by myco BR-AgNPs. The effect of myco BR-AgNPs on the expression of a gene encoding CTX-M-15 was tested on a molecular level, and the observed results showed that the gene expression was reduced when compared with control and antibiotic treatment. According to the current research, myco BR-AgNPs synthesized with the aid of endophytic fungal extract could be used to suppress the growth of ESBL-positive strains of E. coli. Myco BR-AgNPs may be an important alternative to various antibiotics in preventing bacterial resistance if optimized and tested for toxicity.
\end{abstract}

Keywords: Myco silver nanoparticles, Biofilm, CTX-M-15

*Correspondence: hemalatha.sls@bsauniv.ac.in †Tahira Akther and S. Ranjani equal contribution School of Life Sciences, B. S. Abdur Rahman Crescent Institute of Science and Technology, Vandalur, Chennai, TN, India 600048

\section{Background}

Nanotechnology has brought a big revolution in science and technology. Nanomaterial synthesis using metals such as silver, copper, gold, magnesium, iron and titanium has gained immense importance and has attracted many nano-researchers due to their various applications in science and technology $[1,2]$. Nanoparticles are 
versatile agents with numerous applications in biomedical, bioengineering, agriculture, semiconductors, etc. Nanoparticles have the potential to become a powerful nano-weapon against bacteria. [3]. The WHO [4, 5] has expressed a serious concern regarding the upsurge development of antibiotic-resistant microbes. It is commonly believed that above $70 \%$ of bacterial infections show resistance towards the present-day antibiotics that are generally used to treat the infection. Multidrug resistance has become one of the greatest challenges throughout the globe [6]. There are complications in treating infections caused by MDR microbes including Gram-positive and Gram-negative organisms. This opportunistic organism produces a variety of virulence factors, biofilm and pyocyanin, which helps to develop resistance to antibiotics [7].

ESBL-synthesizing bacteria such as Escherichia coli and Klebsiella pneumoniae hydrolyze the beta-lactam ring of antibiotics, thus inactivating the antibiotics and leading to antibiotic resistance. These bacteria cause various diseases such as blood stream infections, urinary tract infections, bloody diarrhoea, pneumonia and skin infections. More than $60 \%$ infections are caused by biofilm-producing bacteria, which create a major obstacle in treating those infections [8]. ESBL-producing $E$. coli have the capability of producing the biofilm which makes them more antibiotic resistant. So far, no drug has been discovered that exactly targets biofilm, so the need of the hour is to find alternative strategies that can help in breaking this antibiotic resistance mediated through biofilm formation [9]. Antibiotic resistance has become difficult to cure life-threatening infections caused by outbreak of drug-resistant bacteria. Hence, there is need for the development of new drugs or modification of existing drugs to control multidrug resistant microbes [10]. Nanotechnology offers a wide platform to develop and modify metals into nanoparticles, which can be utilized for various applications including diagnostics, cell labelling, biomarkers, biological imaging, nano-drugs, drug delivery system, and antimicrobial drugs for treating different diseases [11]. In general, researchers are focussing towards the synthesis of different nanoparticles, especially silver nanoparticles, to tackle the problem with the rise of antibiotic-resistant microbes [12]. From the ancient time people have been utilizing $\mathrm{Ag}$ as an antimicrobial agent because of its strong antimicrobial potential [13]. Antimicrobial efficacy of metallic Ag can be improved by manipulating the size and shape at the nano-level. The smaller size of the nanoparticles as well as their unique physical and chemical properties has made them attractive to use in various fields [14]. The exact mechanisms which the nanoparticles employ on different microbes are still being explored. However, there are several philosophies on the antimicrobial mechanism of NPs, which are (a) NPs release the silver ions and are toxic (b) formation of free radicals (c) interaction of silver NP with thiol groups hence arresting cell cycle by inactivating membrane-bound enzymes [15]. It is also known that the smaller nanoparticles have a larger surface area which enhances the interaction potential of the nanoparticles, thus shows the strongest antimicrobial effects. The charge on the surface of metal nanoparticles abridges the attachment on the bacterial surface which regulates their bactericidal effect. The bactericidal efficacy of NPs is also dependent on size and shape [15].

Nanoparticles are gaining a considerable attention day by day due to their unique properties and are being widely studied because of their diverse applications in different fields. Nowadays for nanoparticle synthesis researchers are utilizing different biological sources including plants, yeast, bacteria, actinomycetes and fungi [16]. In addition, endophytic fungi are more ideal for the synthesis of nanoparticles and can be readily grown in the laboratory on a large scale, which can withstand flow pressure, agitation and other extreme conditions in the bioreactors or other chambers [17]. Hence, this current research mainly focuses on studying the antibacterial effect of endophytic fungal extract-mediated silver nanoparticles on ESBL-producing pathogenic E. coli.

\section{Materials and methods}

\section{Bacterial strains}

Collection of American Type Culture Collection ATCC strains of E. coli (ATCC 25,922) was utilized. Luria-Bertani agar was used to prepare slant cultures. The clinical isolates of Escherichia coli were collected from Tagore Medical College and Hospital, Chennai. The clinical strains were obtained (BSAU: REG-OFF: 2016/02SLS) after proper ethical approval by the institutional ethics committee. All the strains have been maintained as stocks in $20 \%$ glycerol and slant cultures.

\section{Antimicrobial activity of clinical strains of $E$. coli through well plate method}

The antibacterial potential of myco BR-AgNPs was tested through well diffusion method on LB agar plates [18]. $100 \mu \mathrm{l}$ of E. coli ATCC (25922) and resistant clinical strain cell suspension with cell density of 0.5 McFarland standard units were spread on LB agar plates and wells were made and loaded with $50 \mu \mathrm{l}$ of mycosilver nanoparticles. Antibiotic was used as a positive control. The plates were incubated for $24 \mathrm{~h}$ at $37^{\circ} \mathrm{C}$ and the zone of inhibition was calculated by the diameter measured around the wells. 


\section{Minimum inhibitory concentration (MIC) and minimum bactericidal concentration (MBC) of mycosilver nanoparticles}

Broth dilution method was used to determine the antimicrobial potency of mycosilver nanoparticles [19]. The MIC was determined in LB broth through serial dilution of different concentrations of mycosilver nanoparticles by using a 96-well microplate. Later $10 \mu \mathrm{l}$ of fresh bacterial culture (0.5 McFarland's standard) was pipetted into each well. Bacterial culture without mycosilver nanoparticles was kept as positive control and broth without culture were kept as negative control and mycosilver nanoparticles as test. The 96-well microplate was incubated at $37^{\circ} \mathrm{C}$ for $24 \mathrm{~h}$. MIC of mycosilver nanoparticles was noted before and after incubation by observing the turbidity of the growth in 96-well plate to confirm its minimum inhibitory concentration for the ATCC (25922) and clinical resistant strains of $E$. coli. Aliquots of $100 \mu \mathrm{l}$ from wells without visual growth were inoculated on LB agar plates and incubated for $24 \mathrm{~h}$ at $37^{\circ} \mathrm{C}$ temperature. LB agar plates were observed to monitor the bacterial growth to determine the MBC [20-22].

\section{Biofilm formation assay}

The efficacy of BR-mycosilver nanoparticles on the biofilm formation was determined by quantifying the biofilm formation through crystal violet assay [23]. Overnight culture (0.2 OD at $600 \mathrm{~nm}$ ) of ATCC and clinical resistant strains of $E$. coli were added into $1 \mathrm{~mL}$ of fresh LB broth. Biofilm assay was carried out in LB broth in the presence and absence of mycosilver nanoparticles in a 96-well microplate. Bacteria were allowed to stick and grow with gentle agitation for $24 \mathrm{~h}$ at $37{ }^{\circ} \mathrm{C}$. After incubation, broth containing non-adherent cells were removed and washed with sterile distilled water. The adherent bacterial cells were stained with $125 \mu \mathrm{l}$ of $0.1 \%$ crystal violet for $10 \mathrm{~min}$. After incubation, crystal violet was removed completely by washing with distilled water and $200 \mu \mathrm{l}$ of $30 \%$ acetic acid was added into each well to dissolve the crystal violet. The biofilm formation was quantified by measuring the absorbance at A595 by using the Multimode reader (Perkin Elmer, USA, 2013) [24-27].

\section{DNA isolation and polymerase chain reaction}

E. coli ATCC $(25,922)$ and resistant strains of $E$. coli were grown with and without myco AgNPs overnight in LB broth. Template DNA from both the strains was prepared by centrifuging the overnight culture and discarding the supernatant. The pellet was washed with water for 2-3 times. In $150 \mathrm{ml}$ of sterile water pellet was suspended and suspension was prepared. The suspension was boiled with the help of the thermostat for bacterial cell lysis at
$95{ }^{\circ} \mathrm{C}$ for $10 \mathrm{~min}$. The obtained lysate was kept at room temperature for cooling down. After cooling, the lysate was centrifuged for $5 \mathrm{~min}$ at $12,000 \mathrm{rpm}$ and the supernatant was used for PCR amplification as template DNA [28]. Master cycler nexus gradient (Eppendorf, USA) was used for PCR amplification. The reaction mixture contained $5 \mu \mathrm{l}$ of Master Mix, $1 \mu \mathrm{l}$ each of 1 M CTX-M15 forward (5'-CACGTCAATGGGACGATGT-3') and reverse (5'GAAAGGCAATACCACCGGT-3') primers and $3 \mu \mathrm{l}$ of genomic DNA. PCR steps included an initial denaturation for $30 \mathrm{~s}$ at $94{ }^{\circ} \mathrm{C}$, denaturation for $30 \mathrm{~s}$ at $95{ }^{\circ} \mathrm{C}$, annealing at $58{ }^{\circ} \mathrm{C}$ for $30 \mathrm{~s}$ and, extension for $60 \mathrm{~s}$ at $70{ }^{\circ} \mathrm{C}$ and a final extension for $600 \mathrm{~s}$ at $72{ }^{\circ} \mathrm{C}$. The overall reaction comprised 35 cycles. The amplified PCR product was run on an agarose gel using $1 \mathrm{X}$ TAE buffer and 100 bp DNA ladder (Gene Direx). Gel was stained with ethidium bromide and scanned under Chemi Doc (Bio-Rad) [29-32].

\section{Gene expression analysis}

This analysis was conducted to visualize the impact of myco AgNPs on gene encoding CTX-M-15 expression in E. coli. CTX-M-15 positive strains were treated with their MICs concentration of myco AgNPs and untreated strain was kept as positive control and E. coli ATCC (25922) strain was kept as negative control. An antibiotic (ampicillin, $30 \mu \mathrm{g} / \mathrm{ml}$ ) was also used to treat $E$. coli strains. The genomic DNA extracted from all the strains were amplified with a specific primer for CTX-M-15 followed by gel electrophoresis and the amplicon [29-33] was observed.

\section{Statistical analysis}

In this study, all the experimental data were analysed using GraphPad prism (v6) and using Microsoft Excel 2013. The data acquired were presented as mean $\pm S E M$, $N=3$ and $p<0.05$ considered as significant.

\section{Results and discussion \\ Detection of phenotypic ESBL and antibiotic sensitivity test}

Out of 83 clinical isolates, $82 \%$ was found to be resistant to at least one of the third and fourth generation antibiotics including cephalosporins or ampicillin. In the CLSI phenotypic confirmatory test using 3rd and 4th generation cephalosporin/clavulanic acid combination antibiotic disc, all the 78 strains were analysed are highly susceptible to ceftazidime, cefotaxime, cefepime and amoxicillin in the presence of clavulanic acid, thereby confirmed the production of ESBL by these clinical isolates of E. coli. The isolates showed positive for at least one of the confirmatory tests and by utilizing CAZ/CLA, CTX/CLA, CPM/CLA, and AMX/AMC disk. 
Antibiotic susceptibility test results revealed that all the strains of $E$. coli were resistant to antibiotics including cefepime $(30 \mu \mathrm{g})$, ampicillin $(10 \mu \mathrm{g})$, ceftazidime $(30 \mu \mathrm{g})$, amoxicillin $(30 \mu \mathrm{g})$, cefotaxime $(30 \mu \mathrm{g})$, cefpodoxime $(10 \mu \mathrm{g})$, cefotetan $(30 \mu \mathrm{g})$, ciprofloxacin $(5 \mu \mathrm{g})$, levofloxacin $(5 \mu \mathrm{g})$, gentamicin $(30 \mu \mathrm{g})$, aztreonam $(30 \mu \mathrm{g})$, meropenem $(10 \mu \mathrm{g})$ and imipenem $(10 \mu \mathrm{g})$ while some strains were mostly sensitive to imipenem $(10 \mu \mathrm{g})$ and meropenem $(10 \mu \mathrm{g})$ and apart from these two imipenem $(10 \mu \mathrm{g})$ and meropenem $(10 \mu \mathrm{g})$ only few strains were sensitive to the antibiotics shown in our previous paper [34].

\section{Antibacterial activity through well plate method}

In our previous paper, we have synthesized and characterized the mycosilver nanoparticles from endophytic fungi Botryosphaeria rhodina isolated from Catharanthus roseus [35] plants. The synthesis of Myco BR-AgNPs was confirmed using UV-visible spectra. After confirmation, synthesized nanoparticles were purified by using centrifugation techniques with repeated washing using ultrapure water. The obtained pellet of purified nanoparticles was dried completely to fine powder and dissolved in water at the concentration of $1 \mathrm{mg} / \mathrm{ml}$. Myco BR-AgNPs were characterized by TEM microscopic technique and the size was observed at $10 \mathrm{~nm}$ range and showed the average size $<20 \mathrm{~nm}$ and were spherical in shape [35]. Myco BR-AgNPs were tested against ATCC (25922) and resistant ESBL-producing pathogenic strains of $E$. coli through the well diffusion method. Antibiotic ampicillin was used as a positive control and other wells were loaded with $50 \mu \mathrm{l}$ of $1 \mathrm{mg} / \mathrm{mL}$ Myco AgNPs displayed respectable zones of inhibition (Fig. 1). Ampicillin was used as an antibiotic control displayed no zone because the strains were resistant to this antibiotic, whereas ATCC strain showed prominent zone of inhibition.

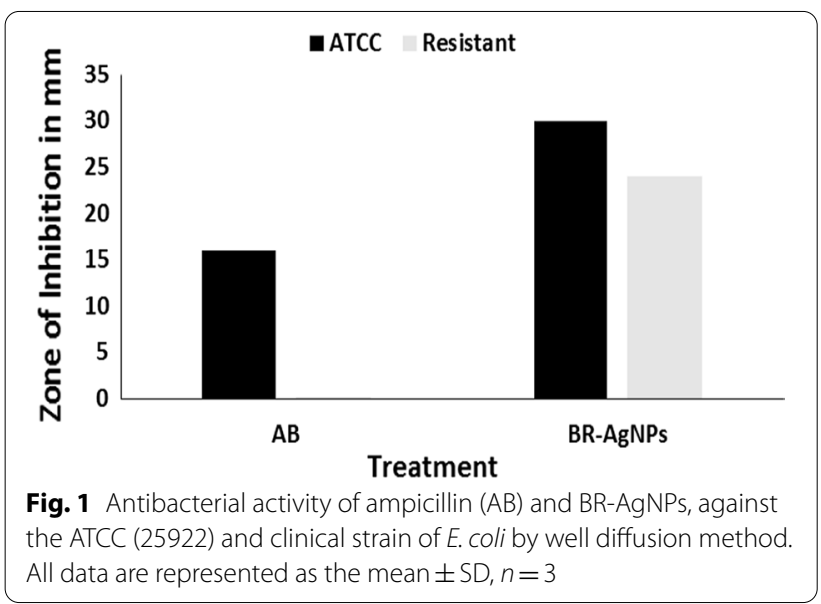

MIC and MBC of myco BR-AgNPs against the ATCC $(25,922)$ and clinical resistant strains of $E$. coli

E. coli ATCC $(25,922)$ and resistant strain of $E$. coli were treated with myco BR-AgNPs and incubated for $24 \mathrm{~h}$ at $37{ }^{\circ} \mathrm{C}$. For MIC determination, the plates were visually observed and MIC was taken as the concentration of myco BR-AgNPs where no visible growth was found. MIC values of these strains are presented in Table 1 , the highest value for MIC $(1.25 \mu \mathrm{g} / \mathrm{ml})$ for ESBL-producing E. coli strain and the lowest value $(0.078 \mu \mathrm{g} / \mathrm{ml})$ was observed for ATCC $(25,922)$ E. coli strain. The spectrophotometric reading (A600) of MIC plate was measured by using microplate reader. Figure 2 displays the decrease in the growth percentage for ATCC $(25,922)$ and clinical strain of $E$. coli treated with myco BR-AgNPs at different concentrations.

MBC of myco BR-AgNPs against ATCC (25922) and clinical resistant strains of $E$. coli was studied via surface drop method where all the MIC dilutions were overlaid on sterile LB agar plates. The LB agar plates were incubated for $12-24 \mathrm{~h}$ at $37{ }^{\circ} \mathrm{C}$ and were observed for any bacterial growth. The $\mathrm{MBC}$ value of the myco AgNPs were found in the range of $0.156-1.25 \mu \mathrm{g}$ for both the strains of E. coli. The MIC, MBC values and their tolerance level of both the strains are displayed in Table 1. The tolerance levels of both the strains of E. coli treated with myco AgNPs were calculated. The MBC /MIC ratio defines a specific antibacterial agent's bactericidal or bacteriostatic property. The $\mathrm{MBC} / \mathrm{MIC}$ ratio of $\geq 16$ indicates that antibacterial agent is bacteriostatic while the ratio $\leq 4$ indicates that the antibacterial agent is bactericidal. E. coli strains displayed a tolerance level of 2 and 4 which concludes that the myco BR-AgNPs were bactericidal for ATCC (25922) and resistant strains of E. coli. It can be interpreted from the results that myco BR-AgNPs were effective in both ATCC (25922) and the resistant $E$. coli strains.

\section{Myco BR-AgNPs inhibited the biofilm formation in ATCC (25922) and clinical resistant strains of $E$. coli}

The efficacy of myco BR-AgNPs on biofilm formation in both the strains of $E$. coli was carried out by using a

Table 1 MIC, MBC and tolerance levels of myco BR-AgNPs against ATCC (25922) and resistant E. coli strains, respectively

\begin{tabular}{lll}
\hline Treatment & $\begin{array}{l}\text { E. coli ATCC } \\
(\mathbf{2 5}, \mathbf{9 2 2})\end{array}$ & $\begin{array}{l}\text { ESBL- } \\
\text { producing } \\
\text { resistant } \text { E. coli }\end{array}$ \\
\hline $\mathrm{MIC}(\mu \mathrm{g} / \mathrm{ml})$ & 0.078 & 0.625 \\
$\mathrm{MBC}(\mu \mathrm{g} / \mathrm{ml})$ & 0.312 & 1.25 \\
Tolerance level MBC/MIC & 4 & 2
\end{tabular}

All data are represented as the mean $\pm S D, n=3$ 


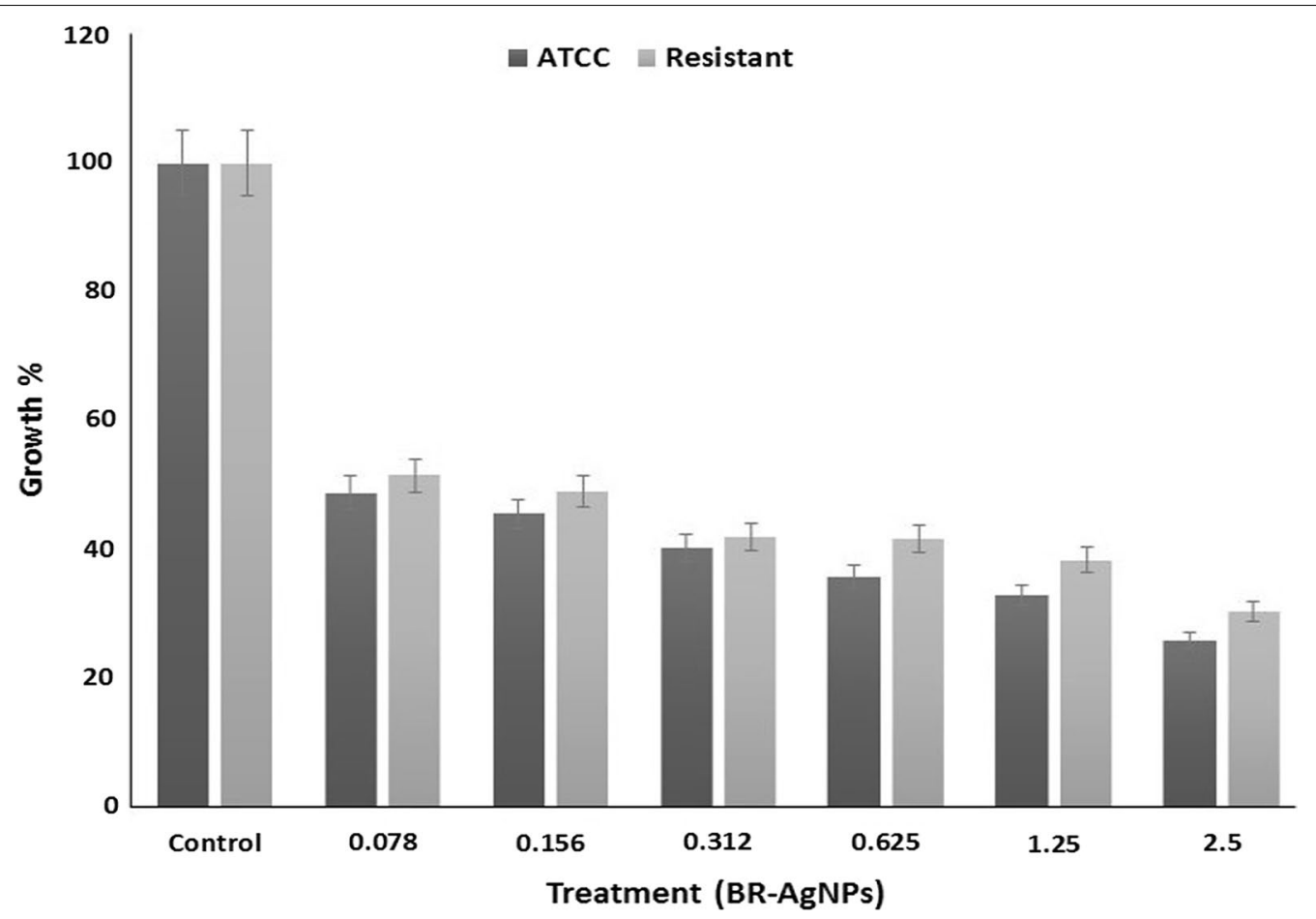

Fig. 2 Effect of myco BR-AgNPs $(\mu \mathrm{g})$ on growth in ATCC $(25,922)$ and clinical resistant strains of E. coli. All data are represented as the mean \pm SD, $n=3$

96-well microplate through serial microdilution. It was observed that BR-AgNPs were able to inhibit the biofilm formation in both the strains and was recorded at $595 \mathrm{~nm}$ by using spectrophotometric measurements. Results also revealed that $2.5 \mu \mathrm{g} / \mathrm{ml}$ of myco BR-AgNPs were more efficient in inhibiting the biofilm formation in ATCC (25922) and resistant strain of E. coli compared to the control (Fig. 3).

\section{Analysis of expression of gene encoding CTX-M-15 in E. coli treated with myco BR-AgNPs}

The effect of myco BR-AgNPs on expression of CTXM-15 gene in E. coli was analysed and compared with $E$. coli strains treated with antibiotic and in control. In $E$. coli strains treated with mycosilver nanoparticles, expression of CTX-M-15 gene was downregulated, and the expression is not changed in control and antibiotic treated strains (Fig. 4). This suggested that the mycosilver nanoparticles are interfering at the transcription level to inhibit the growth of the MDR strains and to abolish the expression of the CTX-M-15 (virulence gene). CTX-M-15 gene is related to the antibiotic resistance and plays a key role in the production of ESBLs.

\section{Discussion}

The current study is focused on the effect of myco BRAgNPs on growth and biofilm formation in E. coli ATCC (25922) and ESBL-producing E. coli strains. The endophytic fungal extract-mediated nanoparticle myco BRAgNPs was synthesized from Botryosphaeria rhodina isolated from medicinal plant $C$. roseus. The extracellular cell filtrate enriched with secondary metabolites of endophytic fungi was harnessed as a reducing and capping agent during nanoparticle synthesis. Our previously published paper was the very first report to utilize endophytic fungi Botryosphaeria rhodina extracellular extract for the synthesis of nanoparticles [35]. In this research work, the experiments on determining the MIC and $\mathrm{MBC}$ concludes that myco nanoparticles effectively inhibit and kill the growth of all test organisms used in this study. There was a dose-dependent activity of nanoparticles upon killing the bacterial strain. With the maximum concentration of $2.5 \mu \mathrm{g} / \mathrm{ml}$ the growth was reduced to $75 \%$ and $70 \%$ for E. coli ATCC (25922) strain and ESBL-producing $E$. coli. With the minimum concentration of $0.078 \mu \mathrm{g} / \mathrm{ml}$, the growth rate was reduced upto $50 \%$ for ATCC (25922) and 48\% for ESBL-producing $E$. coli. There are several reports on antibacterial efficacy of silver nanoparticles. There were several hypothesis 


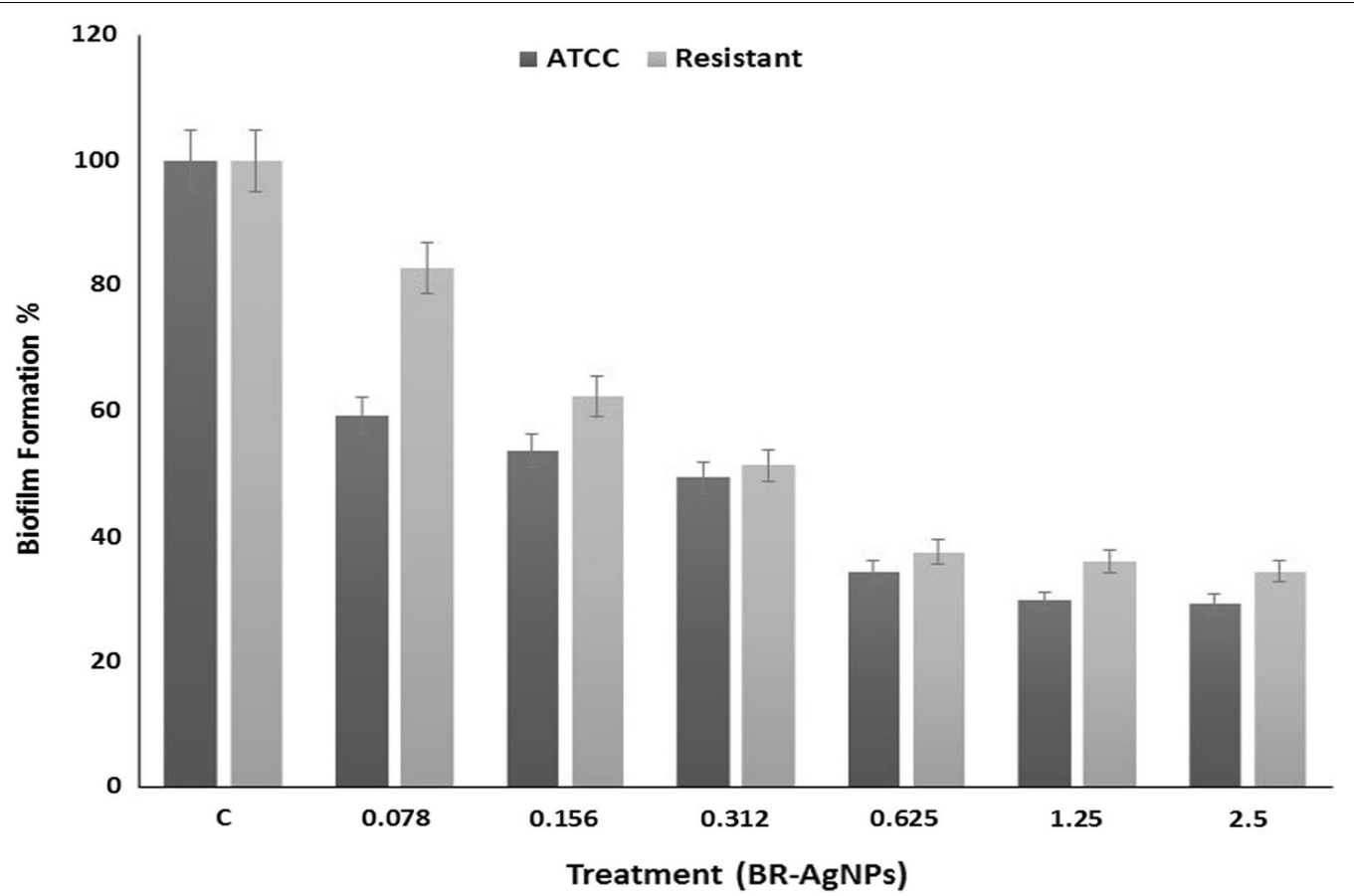

Fig. 3 Reduction of biofilm formation in ATCC $(25,922)$ and ESBL-producing strains of E. coli treated with myco BR-AgNPs (C is the Control). All data are represented as the mean $\pm S D, n=3$

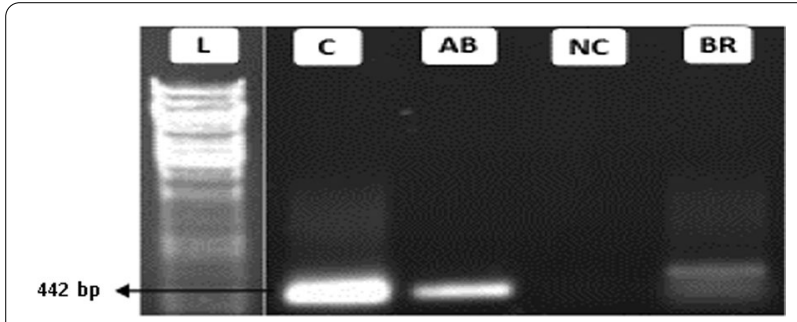

Fig. 4 Analysis of expression of gene by PCR. In clinical strain of $E$. coli, the expression of gene encoding CTX-M-15 in CTX-M-15 positive strains was downregulated when treated with mycoBR-AgNPs. (L DNA ladder, $C$ positive control; $A B$ treatment with an antibiotic; $N C$ Negative control, BR myco BR-AgNPs, respectively, treatment. All data are represented as the mean $\pm S D, n=3$

postulated for its mechanism of action in killing the bacterial cell. The possible mechanism of myco BR-AgNPs is that spherical shaped nanoparticles can easily adhere to the cell wall of bacteria, and it may start creating pits on the surface. This results in structural changes followed by series of consequences, which ultimately results in cell lysis and cell death [15].

Formation of biofilm is an important characteristic feature of bacteria that helps to control the spread of antimicrobial agents within the bacterial cell, resulting in increased resistance. Biofilm also enables bacteria to sustain in harsh environment that make chronic bacterial infections easier [36]. Biofilms are complex structure with consortium of bacteria enclosed in an extra polymeric substances (EPS) matrix. Infection caused by biofilm-causing bacteria is difficult to treat, hence there is a need to find alternative biofilm inhibitors. Previous studies have reported that different types of NPs inhibited the biofilm formation in ESBL-producing $E$. coli strains [37]. The experiment on biofilm formation in ATCC (25922) and ESBL-producing strains of E. coli confirms that myco BR-AgNPs effectively control the formation of biofilm upto 70\% and 60\% for ATCC (25922) and ESBLproducing strains of $E$. coli at the concentration of $2.5 \mu \mathrm{g} /$ $\mathrm{ml}$. The formation of biofilm was also dose dependent. Our results suggest that biofilm formation was inhibited in ATCC (25922) and ESBL-producing strains of E. coli might be because of the disruption of the EPS effectively at the concentration of $0.078 \mu \mathrm{g} / \mathrm{ml}$. Further increasing the concentration of myco BR-AgNP can completely prevent the formation of biofilm. Thus, our myco BR-AgNPs proved to be an effective in reducing the biofilm formation even at lower concentration.

Among the most significant factors in ESBL is a gene encoding CTX-M-15 that plays an important role in the production of ESBL and this gene is more predominant in India [38]. In this present study, CTX-M-15 expression was downregulated when treated with myco BR-AgNPs. 
In northern European countries, resistant strains of $E$. coli are rising, however, the occurrence of ESBL-producing organisms are low [39]. ESBL are most dominating in the eastern and southern European nations. CTX-M-15 is the world's most prevalent genetic constitution accompanied by CTX-M-14 in the Scandinavian countries. In Spain, CTX-M-14 is the utmost prevalent, but in Poland and Barcelona, CTX-M-9 was also found [40]. CTX-M15 and CTX-M-14 are more prevalent in India [41]. In South America, CTX-M-2 and CTX-M- 8 are distinctive phylogroups [42]. The percentage of ESBL-producing bacteria type CTX-M is therefore growing globally [43]. At least the fast spread and development of these challenging bacterial strains should be slowed down. The gut microbiome is an optimal pool for the development of drug-resistant genes of healthy individuals and inhabited patients, a place of the clonal spread of resistant bacteria, or horizontal gene transfer. Previous studies have mentioned about the effectiveness of AgNPs, CuNPs and $\mathrm{ZnO}$ NPs on the growth of ESBLs-producing bacteria [44]. In the present study, we clearly explained the antibacterial, antibiofilm and ESBL- CTX-M-15-suppressing activity of myco BR-AgNPs in ESBL-producing strains of $E$. coli with standard E. coli ATCC (25922) strain as a control.

\section{Conclusion}

In the present study, the effect of myco BR-AgNPs was studied in ESBL-positive strains of E. coli. Antibacterial potential of myco AgNPs was determined by MIC, MBC, and inhibition of biofilm and downregulation of CTX-M15 gene. The myco AgNPs inhibited the growth of ESBLs strains and reduced the biofilm formation as compared to untreated strains (control), in all the strains used in this study. Differential expression of the gene encoding CTXM-15 was observed when treated with myco AgNPs when compared to the untreated strains. It was manifested that the myco BR-AgNPs showed antibacterial activity and reduced biofilm formation in ESBL-positive strains of E. coli. The mechanism of bacterial killing by AgNPs is damaging the cell membrane followed by the generation of ROS. Thus, myco BR-AgNPs are the alternative choice for treating MDR bacterial infections. These myco AgNPs could be utilized to treat MDR pathogens in a wide range of pharmaceuticals as well as in the medical field.

\footnotetext{
Acknowledgements

The authors are also thankful to B.S. Abdur Rahman Institute of Science \& Technology, Chennai, for providing research facilities in School of Life Sciences.
}

\section{Authors' contributions}

TA, RS: formal analysis, investigation, writing original draft. HS: conceptualization, supervision and editing. All authors read and approved the final manuscript.
Funding

Not applicable.

\section{Availability of data and materials}

The datasets obtained and analysed in the current study are available from the corresponding author on reasonable request.

\section{Declarations}

Ethics approval and consent to participate

Not applicable.

Consent for publication

Not applicable.

Competing interests

The authors declare that they have no competing interests.

Received: 8 March 2021 Accepted: 2 July 2021

Published online: 13 July 2021

\section{References:}

1. El-Kassas HY, Mohamed AA (2017) Phytotoxic effects of sea weed mediated copper nanoparticles against harmful alga: Lyngbya majuscule. J Genet Eng Biotechnol 15:41-48

2. Rajesh kumar S, (2016) Anticancer activity of eco-friendly gold nanoparticles against lung and liver cancer cells. J Genet Eng Biotechnol 14(1):195-202

3. Li X, Xu H, Chen ZS, Chen G (2011) Biosynthesis of nanoparticles by microorganisms and their applications. J Nanomater. https://doi.org/10. $1155 / 2011 / 270974$

4. Ubaid R, Hemalatha S (2019) Effect of biosynthesized copper nanoparticles (Cunps) on growth and biofilm formation in fluconazole resistant Candida albicans. J Microbiol Biotechnol Food Sci 9:21-24

5. Cabot G, Zamorano L, Moyà B, Juan C, Navas A, Blázquez J, Oliver A (2016) Evolution of Pseudomonas aeruginosa antimicrobial resistance and fitness under low and high mutation rates. Antimicrob Agents Chemother 60:1767-1778

6. Shaikh S, Fatima J, Shakil S, Rizvi SMD, Kamal MA (2015) Antibiotic resistance and extended spectrum beta-lactamases: Types, epidemiology and treatment. Saudi Journal of Biological Sciences 22:90-101

7. Girard G, BloembergGV, (2008) Central role of quorum sensing in regulating the production of pathogenicity factor in Pseudomonas aeruginosa. Future Microbiol 3:97-106

8. Ansari MA, Khan HM, Khan AA, Cameotra SS, Pal R (2014) Anti biofilm efficacy of silver nanoparticles against biofilm of extended spectrum b-lactamase isolates of Escherichia coli and Klebsiella pneumoniae. ApplNanosci 4:859-868

9. Bush K, Jacoby GA (2009) Updated functional classification of -lactamases. Antimicrob Agents Chemother 54(3):969-976

10. Humberto H, Lara V, Ayala-Nunez NV, Carmen LD, Ixtepan T, Cristina RP (2010) Bactericidal effect of silver nanoparticles against multidrug-resistant bacteria. World J Microbio Biotech 26:615-621

11. Singh R, Singh NH (2011) Medical applications of nanoparticles in biological imaging, cell labeling, antimicrobial agents, and anticancer nano drugs. J Biomed Nanotech 7:489-503

12. Gemmell CG, Edwards DI, Frainse AP (2006) Guidelines for the prophylaxis and treatment of methicillin-resistant Staphylococcus aureus (MRSA) infections in the UK. J Antimicro Chemother 57:589-608

13. Chen X, Schluesener HJ (2008) Nano-silver: a nano product in medical application. Toxico Lett 176:1-12

14. Kim JS, Kuk E, Yu KN, Kim JH, Park SJ, Lee HJ, Jeong DH, Cho MH (2007) Antimicrobial effects of silver nanoparticles. Nanomed Nanotech Bio Med 3:95-101

15. Holt KB, Bard AJ (2005) Interaction of silver(I) ions with the respiratory chain of Escherichia coli: an electrochemical and scanning electrochemical microscopy study of the antimicrobial mechanism of micromolar $\mathrm{Ag}+$. Biochemistry. https://doi.org/10.1021/bi0508542 
16. Besinis A, De Peralta T, Handy RD (2014) The antibacterial effects of silver, titanium dioxide and silica dioxide nanoparticles compared to the dental disinfectant chlorhexidine on Streptococcus mutans using a suite of bioassays. Nanotoxicology 8:1-16

17. MubarakAli D, Gopinath V, Rameshbabu N, Thajuddin N (2012) Synthesis and characterization of CdS nanoparticles using C-phycoerythrin from the marine cyanobacteria. Matrl Lett 74:8-11

18. Alghuthaymi MA, Almoammar H, Rai M, Said-Galiev E, Abd-Elsalam KA (2015) Myconanoparticles: synthesis and their role in phytopathogens management. Biotech Equip 29:221-236

19. Onn ML, Lim PT, Mujahid A, Proksch P, Müller M (2016) Initial screening of mangrove endophytic fungi for antimicrobial compounds and heavy metal bio sorption potential. Sains Malaysiana 45:1063-1071

20. Balouirin M, Sadiki M, Ibnsouda SK (2016) Methods for in vitro evaluating antimicrobial activity: A review. J Pharm Anal 6:71-79

21. Ranjani S, Shariq Ahmed M, Adnan M, Senthil Kumar N, Ruckmani K, Hemalatha S (2020) Synthesis, characterization and applications of endophytic fungal nanoparticles. Inorg Nano-Met Chem 51(2):280-287. https://doi.org/10.1080/24701556.2020.1784231

22. Ranjani S, Shariq Ahmed M, MubarakAli D, Ramachandran C, Senthil Kumar N, Hemalatha S (2020) Toxicity assessment of silver nanoparticles synthesized using endophytic fungi against nosocomial infection. Inorg Nano-Met Chem. https://doi.org/10.1080/24701556.2020.1814332

23. Ranjani S, Das R, Ahmed S, Hemalatha S (2020) Myco-Nanocolloids manipulate growth, biofilm formation and virulence genes in UTI causing E coli. Nano-Met. Chem, Inorg. https://doi.org/10.1080/24701556.2020. 1852426

24. Rao SPN, Prasad SR, Radhakrishna M, Krishna S (2014) Extended spectrum beta -lactamases Producing Escherichia coli and Klebsiella pneumoniae: A Multi centric study across Karnataka. IJCR 6:4621-4626

25. Ranjani S, FaridhaBegum I, Tasneem IK, SenthilKumar N (2020) Hemalatha S (2020) Silver decorated green nanocolloids as potent antibacterial and antibiofilm agent against antibiotic resistant organisms isolated from tannery effluent. Inorg Nano-Met Chem 51(6):823-831. https://doi.org/ 10.1080/24701556.2020.1811326

26. Ranjani S, Salman Al Farzi M, Shruthy Priya P, Waseem M, Ruckmani K, Hemalatha S (2020) Multi potent Aromatic nano colloid: Synthesis, characterization and applications. AMB Expr 10:168. https://doi.org/10.1186/ s13568-020-01104-5

27. Mittal L, Ranjani S, Shariq Ahmed M, Jeya Shree T, Tahira A, Poompavai S, Camarillo IG, GowriSree V, Raji S, Hemalatha S (2020) Turmeric-silver-nanoparticles for effective treatment of breast cancer and to break CTX-M-15 mediated antibiotic resistance in Escherichia coli. Inorg Nano-Met Chem 51(6):867-874. https://doi.org/10.1080/24701556.2020.1812644

28. Ranjani S, Faridha Begum I, Santhoshini J, Senthil Kumar N, Ruckmani K, Hemalatha.S, (2020) Mimosa pudica floral nanoparticles: A potent antibiotic resistance breaker. Inorg Nano-Met Chem. https://doi.org/10.1080/ 24701556.2020.1852429

29. Martinsa M, McCuskera MP, Viveirosb M, Couto I, Fanning S, Pagès JMAmaral L, (2013) A simple method for assessment of MDR bacteria for over-expressed efflux pumps. Open Microbiol J 7:72-82

30. Rasool USP, Parveen A, Sah SK, Hemalatha S (2018) Efficacy of Andrographis paniculata against extended spectrum beta-lactamase (ESBL) producing E. coli. BMC Complement Altern Med 18(1):244
31. Ranjani S, Parthasarathy P, Rameshkumar P, Vimal Kumar U, Hemalatha S (2021) Pungent anti-infective nanocolloids manipulate growth, biofilm formation, and CTX-M-15 gene expression in pathogens causing vibriosis. Aquacult Int 29:859-869. https://doi.org/10.1007/s10499-021-00660-2

32. Ranjani S, Tamanna K, Hemalatha S (2020) Triphala green nano colloids: synthesis, characterization and screening biomarkers. Appl Nanosci 10:1269-1279. https://doi.org/10.1007/s13204-019-01208-w

33. Ranjani S, Shariq Ahmed M, Ruckmani K, Hemalatha S (2020) Green nanocolloids control multi drug resistant pathogenic bacteria. J Clust Sci 31:861-866. https://doi.org/10.1007/s10876-019-01694-6

34. Akther T, Priya S, Kumar SS, Khan MS, Hemalatha S (2019) Ta-AgNps are potential antimicrobial resistance breakers. J Nanostruct 9(2):376-383. https://doi.org/10.1007/s11356-019-04718-w

35. Akther T, Mathipi V, Kumar NS, Davoodbasha MA (2019) Hemalatha S (2019) Fungal-mediated synthesis of pharmaceutically active silver nanoparticles and anticancer property against A549 cells through apoptosis. Environ Sci Pollut Res Int 26(13):13649-13657. https://doi.org/10.1007/ s11356-019-04718-w

36. Yin W, Wang Y, Liu L, He J (2019) Biofilms: the microbial "protective clothing" in extreme environments. Int J Mol Sci 20(14):3423. https://doi.org/ 10.3390/ijms20143423.PMID:31336824;PMCID:PMC6679078

37. Shakerimoghaddam A, Ghaemi EA, Jamalli A (2017) Zinc oxide nanoparticle reduced biofilm formation and antigen 43 expressions in uropathogenic Escherichia coli. Iran J Basic Med Sci 20:451-456

38. Ike Y (2017) Pathogenicity of Enterococci". Nihon Saikingaku Zasshi 72:189-211

39. Brolund A (2014) Overview of ESBL-producing Enterobacteriaceae from a Nordic perspective infection. Ecol Epidemiol 4:1-9

40. Coelho A, Phedra-Carrasco N (2012) Bartolom'e R, Quintero-Zarate JN, Larrosa N, Cornejo-S'anchez T (2012) Role of IncH12 plasmids harbouring blaVIM-1, blaCTX-M-9, aac(60)-Ib and qnrA genes in the spread of multi-resistant Enterobacter and Klebsiella pneumoniae strains in different units at Hospital Valld'Hebron, Barcelona. Spain Int J Antimicrob Agents 39:514-517

41. Sah S, Rasool U, Hemalatha S (2020) Andrographis paniculata extract inhibit growth, biofilm formation in multidrug resistant strains of Klebsiella pneumoniae. J Trad Compl Med 10:599-604

42. Cantón R, González-Alba JM, Galán JC (2012) CTX-M enzymes: origin and diffusion. Front Microbiol 2(3):110. https://doi.org/10.3389/fmicb.2012. 00110.PMID:22485109;PMCID:PMC3316993

43. Bevan ER, Jones AM, Hawkey PM (2017) Global epidemiology of CTX-M $\beta$-lactamases: temporal and geographical shifts in genotype. J Antimicrob Chemother 72(8):2145-2155. https://doi.org/10.1093/jac/dkx146

44. Mohamed MRM, Ahmed SJ (2016) Antibacterial potential of silver nanoparticle synthesized by marine actinomycetes in reference with standard antibiotics against hospital acquired infectious pathogens. Afric J of Biotechn 15:2115-2123

\section{Publisher's Note}

Springer Nature remains neutral with regard to jurisdictional claims in published maps and institutional affiliations.

\section{Submit your manuscript to a SpringerOpen ${ }^{\circ}$ journal and benefit from:}

- Convenient online submission

- Rigorous peer review

- Open access: articles freely available online

- High visibility within the field

Retaining the copyright to your article

Submit your next manuscript at springeropen.com 